\title{
Research on Multi-stage and Multi-objective Production Planning Considering Decision Makers' Preference
}

\author{
Chu Yanfeng, Li Huali
}

To Link this Article: http://dx.doi.org/10.6007/IJARBSS/v9-i5/5839

DOI: $10.6007 /$ IJARBSS/v9-i5/5839

Received: 01 Feb 2019, Revised: 26 March 2019, Accepted: 30 April 2019

Published Online: 18 May 2019

In-Text Citation: (Yanfeng \& Huali, 2109)

To Cite this Article: Yanfeng, C., \& Huali, L. (2109). Research on Multi-stage and Multi-objective Production Planning Considering Decision Makers' Preference. International Journal of Academic Research in Business and Social Sciences, 9(5), 39-51.

\section{Copyright: (C) 2019 The Author(s)}

Published by Human Resource Management Academic Research Society (www.hrmars.com)

This article is published under the Creative Commons Attribution (CC BY 4.0) license. Anyone may reproduce, distribute, translate and create derivative works of this article (for both commercial and non-commercial purposes), subject to full attribution to the original publication and authors. The full terms of this license may be seen at: http://creativecommons.org/licences/by/4.0/legalcode

\section{Vol. 9, No. 5, 2019, Pg. 39 - 51}

Full Terms \& Conditions of access and use can be found at http://hrmars.com/index.php/pages/detail/publication-ethics 


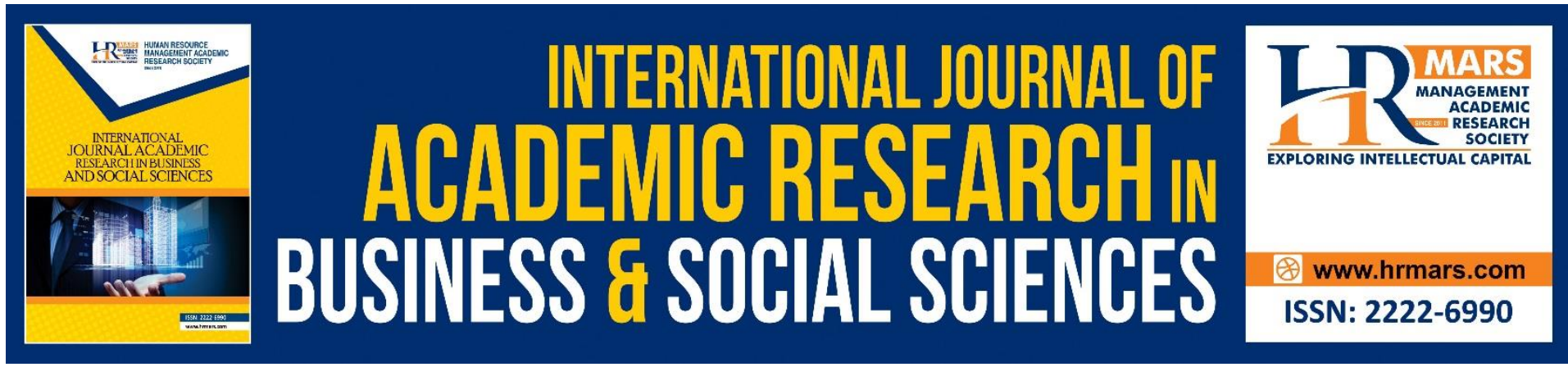

\title{
Research on Multi-stage and Multi-objective Production Planning Considering Decision Makers' Preference
}

\author{
Chu Yanfeng, Li Huali \\ School of Economics and Management, Nanjing University of Aeronautics and \\ Astronautics, Nanjing, China
}

\begin{abstract}
The purpose of the study is to resolve the problem on making production planning of the multi-product, multi-stage and small-batch products when information is uncertain. In this paper, the linear programming model of grey parameters is constructed. Compared with the traditional production planning optimization method, the effectiveness of the production planning is proved. The results will give a range of decision variables, and help decision makers arranging production planning to deal with unavoidable information uncertainty.
\end{abstract}

Keywords: Multi-Stage, Multi-Objective, Production Planning

\section{Introduction}

The multi-stage multi-product production plan is to formulate corresponding production strategies relying on the actual production. Early research on production planning issues was conducted in a defined environment, with all parameters assumed to be deterministic. The lack of flexibility in static optimization methods makes it difficult to adapt to the uncertainties of many data in actual production processes, such as uncertainty in production costs, inventory levels, and labor changes (Song, \& Hu, 2015). Considering the uncertainty of production information, it is more helpful to develop a production plan that meets actual production requirements.

Recent years, the research on uncertain problems has attracted the attention. In the production process, there are many uncertain factors that affect the production process. Currently dealing with uncertain optimization problems, stochastic optimization methods and fuzzy set theory are often used to describe uncertainty. The stochastic optimization design method is extended by Rubinstein on the basis of cross entropy (Birge, \& Louveaux, 2011). It is mainly used to study the probability distributions obeyed by uncertain variables, such as Poisson distribution, normal distribution and conditional distribution. Scholars at home and abroad have conducted detailed research on the application of stochastic optimization. Sun $G$ $Q$ constructed a robust stochastic optimization model for the virtual power plant of electric vehicle based on the randomness and uncertainty of the number of electric vehicles, and proved the importance of considering the influence of uncertainty in the optimal scheduling 
model (Sun, 2017). However, as the research problem increases, the amount of computation of stochastic optimization will increase sharply. When the scale of the model is large, the solution will be very difficult. when the historical data of the random variable is insufficient, the probability distribution of the obtained variable is not reliable. The fuzzy integration operator introduced by Bellman can solve such production problems well, and Zimmermann applies the integration operator to fuzzy linear programming to solve the production problem. because of it can deal with difficult information to express accurately and different fuzzy membership functions can express diverse uncertainties, fuzzy linear programming has been widely used (Afzali, 2016). Khalilidamghani et al. (2015) used multi-product multi-period multi-objective total production planning problem to model the mixed integer programming and fuzzy combination, and solved the model by fuzzy target programming method (Khalilidamghani, 2015). Finally, it was verified by a practical industrial case. In general, the above methods need to collect a large amount of historical data, but in the actual industrial production process, a large amount of reliable production data is difficult to obtain (Qiang, 2016).

In summary, the following research can be done on the production plan:

A) In the multi-product multi-stage multi-production planning model, when the probability distribution function of uncertain parameters is unknown, there are few studies on using the interval gray number to solve the production planning problem under the uncertain environment.

B) From the raw materials to the delivery of the product, only contain one production plan, which covers a wide range and is not conducive to flexible mobility. Moreover, there are many uncertainties in the production process, and it is difficult to collect enough available statistics in the actual production plan. In order to solve the above shortcomings and more objectively describe the uncertainty in the environment, reduce the impact of uncertain parameter fluctuations in all future situations, and accurately express its impact on production planning decisions, the paper studies the production plan for each production stage. The interval gray number is used to characterize the uncertainty parameters. By dividing the production process into phases and studying the production plans for each phase, and then comparing them to the original production planning cycle, the production planning cycle is optimized by designing and building a production planning model that meets the actual target characteristics.

\section{Problem Description}

The raw materials input at each production stage are delivered by the production line transport vehicles from the corresponding stocks according to the schedule, and the output materials are sent to the corresponding buffers. In the manufacturing system, since some production stages of the finished product are final products for some orders, and other orders are only intermediate products, the product types and processing paths are diversified, so the material flows corresponding to each product will cross each other. From the raw material to the delivery of the product form a network structure.

To establish a multi-product multi-objective production planning model, there are several assumptions:

a) Ignoring the shortage of raw materials and the inventory of raw materials;

b) After the current plan is over, the materials are sent to the next production stage or delivered directly;

c) WIP and products in a certain stage are placed in different buffers; 
d) The products the unit inventory area and cost occupied are the same.

\section{Parameter and Variable}

The symbols of the article are shown in Error! Reference source not found.. When the upper and lower limits of the gray value of the parameter value interval are known, the production plan can be formulated according to the following uncertainty linear programming model.

\begin{tabular}{|c|c|}
\hline & Description \\
\hline \multicolumn{2}{|l|}{ Variable } \\
\hline$Q_{i j}$ & $\begin{array}{l}\text { The number of products i manufactured } \\
\text { in the regular time during production } \\
\text { stage } j\end{array}$ \\
\hline $\mathrm{O}_{\mathrm{ij}}$ & $\begin{array}{l}\text { The number of products i manufactured } \\
\text { in the overtime during production stage } \\
j\end{array}$ \\
\hline $\mathrm{h}_{\mathrm{j}}(\otimes)$ & The number of workers in stage $j$ \\
\hline $\mathrm{f}_{\mathrm{j}}(\otimes)$ & $\begin{array}{l}\text { The number of workers laid off in stage } \\
j\end{array}$ \\
\hline $\mathrm{IW}_{\mathrm{ij}}(\otimes)$ & $\begin{array}{l}\text { The inventory of Semi-finished product } i \\
\text { in stage } j\end{array}$ \\
\hline $\mathrm{IP}_{\mathrm{ij}}(\otimes)$ & The inventory of product $i$ in stage $j$ \\
\hline $\mathrm{MD}_{\mathrm{i}, \mathrm{j}^{\prime}, \mathrm{j}}(\otimes)$ & $\begin{array}{l}\text { The Number of processed products } \\
\text { delayed from production stage } j \text { to } \\
\text { production stage } j^{\prime}\end{array}$ \\
\hline \multicolumn{2}{|l|}{ Parameter } \\
\hline$I_{i j}$ & The number of product $i$ in stage $j$ \\
\hline $\mathrm{OP}_{\mathrm{ij}}$ & $\begin{array}{l}\text { The production cost in regular time to } \\
\text { produce one unit of i product in stage } j\end{array}$ \\
\hline $\mathrm{H}_{\mathrm{ij}}(\otimes)$ & $\begin{array}{l}\text { The production cost in overtime to } \\
\text { produce one unit of i product in stage } j\end{array}$ \\
\hline $\mathrm{H}_{\mathrm{j}}$ & The cost to hire one worker in stage $j$ \\
\hline $\mathrm{L}_{\mathrm{j}}$ & The cost to layoff one worker in stage $j$ \\
\hline$\omega_{\mathrm{ij}}$ & $\begin{array}{l}\text { The inventory cost of produce one unit } \\
\text { Semi finished product of i product in }\end{array}$ \\
\hline $\mathrm{p}_{\mathrm{ij}}$ & $\begin{array}{l}\text { stage } j \\
\text { The inventory cost of produce one unit }\end{array}$ \\
\hline $\begin{array}{c}\mathrm{ca}_{\mathrm{i}} \\
\alpha_{\mathrm{i}}(\otimes) \\
\mathrm{TM}_{\mathrm{i} m}\end{array}$ & $\begin{array}{l}\text { of i product in stage } j \\
\text { The penalty coefficient of delay delivery } \\
\text { order }\end{array}$ \\
\hline (1.4) max & $\begin{array}{l}\text { The machine running time produce a } \\
\text { product } i\end{array}$ \\
\hline Ilj & $\begin{array}{l}\text { The maximum available machine } \\
\text { capacity in stage } j \\
\text { Rate of overtime to regular working } \\
\text { hours }\end{array}$ \\
\hline
\end{tabular}




\section{A. Objective Function}

The production planning model is to produce $M$ series products in $N$ consecutive production phase planning cycles, If multiple targets are optimally optimized, multiple conflicting goals need to be coordinated (Nakahara, 1992).

(a)Objective function 1: Production cost function

The production cost in the production planning model mainly considers the cost factors such as normal working and overtime, hiring and dismissing labor, work in process inventory cost, product inventory cost, and delayed delivery. The production planning model does not consider the relatively stable raw material cost, Hydropower and so on.

$\operatorname{Min} \mathrm{Z}_{1}+\mathrm{Z}_{2}+\mathrm{Z}_{3}+\mathrm{Z}_{4}$

$\mathrm{Z}_{1}=\sum_{\mathrm{i} \in \mathrm{M}(\mathrm{j})} \sum_{\mathrm{j}=1}^{\mathrm{T}} \mathrm{Q}_{\mathrm{ij}} \cdot \mathrm{OP}_{\mathrm{ij}}+\sum_{\mathrm{i} \in \mathrm{M}(\mathrm{j})} \sum_{\mathrm{j}=1}^{\mathrm{T}} \mathrm{O}_{\mathrm{ij}} \cdot \mathrm{H}_{\mathrm{ij}}(\otimes)(2)$

$\mathrm{Z}_{2}=\sum_{\mathrm{j}=1}^{\mathrm{N}}\left(\mathrm{h}_{\mathrm{j}}(\otimes) \cdot \mathrm{H}_{\mathrm{j}}+\mathrm{f}_{\mathrm{j}}(\otimes) \cdot \mathrm{L}_{\mathrm{j}}\right)$

$\mathrm{Z}_{3}=\sum_{\mathrm{i} \in \mathrm{W}} \sum_{\mathrm{j}=1}^{\mathrm{N}} \mathrm{IW}_{\mathrm{ij}}(\otimes) \cdot \omega_{\mathrm{ij}}+\sum_{\mathrm{i} \in \mathrm{P}} \sum_{\mathrm{j}=1}^{\mathrm{N}} \mathrm{IP}_{\mathrm{ij}}(\otimes) \cdot \mathrm{p}_{\mathrm{ij}}(4)$

$\mathrm{Z}_{4}=\sum_{\mathrm{i} \in \mathrm{p}} \sum_{\mathrm{j}=1}^{\mathrm{N}} \sum_{\mathrm{j}_{1}>\mathrm{j}}\left(\mathrm{j}^{\prime}-\mathrm{j}\right) \cdot \mathrm{MD}_{\mathrm{i}, \mathrm{j}^{\prime}, \mathrm{j}}(\otimes) \cdot \mathrm{ca}_{\mathrm{i}}$

In the above objective function, $\mathrm{Z1}$ is the production cost; $Z 2$ indicates the sum of labor costs; $Z 3$ refers to the Semi-finished product and product inventory cost of the products in each production stage; in order to ensure the delivery of orders on time, in order to avoid product delay, the designed penalty fee $Z 4$.

(b)Objective function 2: Market satisfaction (product on-time delivery rate)

$Z_{5}=\operatorname{Max}\left\{0,\left[1-\frac{\sum_{i \epsilon p} \sum_{j=1}^{N} \sum_{j_{1}>j}\left(j^{\prime}-j\right) \cdot M D_{i, j^{\prime}, j}(\otimes)}{D(\otimes)_{i j}}\right]\right\}$

\section{B. Constraints}

(a) Constraints on order balance

$D(\otimes)_{i j}=Q_{i j}+O_{i j}+I_{i(j-1)}+D D_{i j}-I_{i j}-D D_{i j}$

This formula represents the balance between the total production process demand and normal production, overtime production, deferred delivery, and inventory quantity; Using the interval gray number representation $D(\otimes)_{i j}=\left[\underline{D}_{i j}, \bar{D}_{i j}\right], \underline{D}_{i j}$ and $\overline{\mathrm{D}}_{i j}$ Represents the minimum and maximum market demand that may occur during the $j$ production phase of the plan period.

\section{(b) Constraints on Production material}

Material balance is as follows eq. (8). For the production stage of $\forall \mathrm{i} \in \mathrm{W}, \mathrm{j} \in \Phi_{(\mathrm{i})}$ can be used, and the subsequent production stage of the material output using the production stage can be represented by $j^{\prime} \in H(j, i)$, which also describes the production during production path. In the multi-product multi-stage production process, some work-in-progress is the final product for some orders, so the variable $U P_{i j}$ indicates the inventory quantity of the WIP as a directly deliverable product, and the eq. (9) limits the material as the subsequent production stage. Work in products flow into product inventory.

$I W_{i, j+1}=I W_{i, j}+\sum_{j \in \Phi(i)} M_{i^{\prime}, j}$

$-\sum_{i \prime \in \Pi(j, i)} \sum_{j \prime \in H(j, i)} \sum_{j \in \Phi(i)} M_{i^{\prime}, j^{\prime}}-U P_{i j}$

$\forall \mathrm{i} \in \mathrm{W} \mid i^{\prime}, j^{\prime} \notin \emptyset U P_{i j}=0, \forall i \in W-P, \forall j$ 


\section{(c) Constraints on Labor Production Time}

eq. (10) represents the change in the quantity before and after the labor quantity in a certain production stage $j$. The formula indicates that the regular working hours in each planning period is less than the maximum labor constraint, and $\lambda$ is the unit labor working time. Equation (12) represents the overtime time in each planning period, and $\eta_{j}$ refers to the ratio of overtime to regular working hours.

$W_{j_{k}}=W_{j_{k-1}}+h(\otimes)_{j}-f(\otimes)_{j}$
$\sum_{i=1}^{N} e_{i}(\otimes) Q_{i j} \leq \lambda W_{j} \quad \forall j$
$\sum_{i=1}^{N} e_{i}(\otimes) O_{i j} \leq \eta_{j} \lambda W_{j} \quad \forall j$

\section{(d) Constraints on production capacity}

In order to ensure the safety and stability limits the production capacity by limiting the daily running time of the equipment in each production stage.

$\sum_{i=1}^{N} \alpha_{i}(\otimes)\left(Q_{i j}+O_{i j}\right) \leq T M_{j \max }(\otimes)$

\section{(e) Constraints on inventory}

$\sum_{i \in W} I W_{i j} v_{i}(\otimes) \leq I W_{j} U_{\max } \quad \forall j$

$\sum_{\mathrm{i} \in \mathrm{P}} \mathrm{IP}_{\mathrm{ij}} \mathrm{v}_{\mathrm{i}} \mathrm{U}_{\max } \leq \mathrm{IP}_{\mathrm{j}} \mathrm{U}_{\max } \quad \forall \mathrm{j}$

2.3.6Non-negative constraints on variable

$Q_{i j}, O_{i j}, I_{i j}, D D_{i j}, I W_{i j}, M_{i j}, W_{j}, T M_{j}, U I W_{j}, U I P_{j} \geq 0 \forall \mathrm{i}, \forall \mathrm{j}$

\section{Grey Paramrter Linea Rproduction Planning Model}

\section{A. Grey parameter linear programming}

The general formula for gray parameter linear programming is:

$$
\operatorname{minf}(\mathrm{x})=C(\otimes)^{T} X
$$

s.t. $\mathrm{g}_{\mathrm{u}}(\mathrm{X})=\mathrm{A}(\otimes) \mathrm{X}-\mathrm{b}(\otimes) \leq 0, \mathrm{u}=1,2, \ldots, \mathrm{m} \quad$ (18)

$$
h_{v}(X)=B(\otimes) X-d(\otimes)=0, v=1,2, \ldots, m \text { (19) }
$$

And,

$$
\begin{aligned}
\mathrm{X}=\left[\mathrm{x}_{1}, \mathrm{x}_{2}, \ldots, \mathrm{x}_{\mathrm{n}}\right]^{\mathrm{T}} & \\
\mathrm{C}(\otimes) & =\left[C_{1}(\otimes), C_{2}(\otimes), \ldots, C_{n}(\otimes)\right]^{T}, c_{i}(\otimes) \in\left[\underline{c}_{i}, \bar{c}_{i}\right], \mathrm{i}=1,2, \ldots, \mathrm{n} \\
\mathrm{A}(\otimes) & =\left[a_{u j}(\otimes)\right]_{m \times n^{\prime}}, a_{u j}(\otimes) \in\left[\underline{a}_{u j}, \bar{a}_{u j}\right] \quad \mathrm{B}(\otimes)=\left[b_{v j}(\otimes)\right]_{p \times n^{\prime}}, b_{v j}(\otimes) \in\left[\underline{b}_{v j}, \bar{b}_{v j}\right] \\
\mathrm{b}(\otimes) & =\left[b_{1}(\otimes), b_{2}(\otimes), \ldots, b_{m}(\otimes)\right]^{T}, b(\otimes) \in[\underline{b}, \bar{b}] \\
\mathrm{d}(\otimes) & =\left[d_{1}(\otimes), d_{2}(\otimes), \ldots, d_{p}(\otimes)\right]^{T}, d(\otimes) \in[\underline{d}, \bar{d}]
\end{aligned}
$$

The above LPGP model cannot be directly solved by the traditional optimization method, and the uncertain objective function and the constraint need to be transformed into the corresponding equivalent deterministic equations respectively.

\section{B. Uncertain objective function transformation}

The parameter in the objective function is the interval gray number, Ma L H[6] summarized five common order relationships between two interval numbers.

(a) $a(\otimes) \leq_{\mathrm{LU}} b(\otimes), a(\otimes)^{L} \leq b(\otimes)^{L}$ and $a(\otimes)^{U} \leq b(\otimes)^{U}$

And, $a(\otimes)^{L}=\underline{a}, b(\otimes)^{L}=\underline{b}, a(\otimes)^{U}=\bar{a}, b(\otimes)^{U}=\bar{b}, \leq_{\mathrm{LU}}$ represents a decision maker's preference for a higher gray limit and a higher limit for an interval gray number. 
(b) $a(\otimes) \leq_{C R} b(\otimes), a(\otimes)^{C} \leq b(\otimes)^{C}$ and $a(\otimes)^{\mathrm{R}} \geq b(\otimes)^{\mathrm{R}}$

And, $a(\otimes)^{C}=\frac{\underline{a}+\bar{a}}{2}, b(\otimes)^{C}=\frac{\underline{b}+\bar{b}}{2}, a(\otimes)^{R}=\frac{\bar{a}-\underline{a}}{2}, b(\otimes)^{R}=\frac{\bar{b}-\underline{b}}{2}, \leq_{\mathrm{CR}}$ represents decision makers' preference for high grays and low grays.

(c) $a(\otimes) \leq_{\mathrm{LC}} b(\otimes), a(\otimes)^{L} \leq b(\otimes)^{L}$ and $a(\otimes)^{C} \leq b(\otimes)^{C}$

$\leq_{\mathrm{LC}}$ represents the decision maker's preference for a range gray number with a high lower

limit and a higher mean.

(d) $a(\otimes) \leq_{\mathrm{L}} b(\otimes), a(\otimes)^{L} \leq b(\otimes)^{L}$

$\leq_{\mathrm{L}}$ indicates that the decision maker is of a conservative type, preferring the interval gray

number with a higher lower bound.

(e) $a(\otimes) \leq_{\mathrm{U}} b(\otimes), a(\otimes)^{U} \leq b(\otimes)^{U}$

$\leq_{\mathrm{U}}$ represents the decision maker's preference for a higher cap on a range of gray numbers

indicates that the decision maker is more optimistic.

Therefore, the uncertain objective function can be converted into the following deterministic function.

$\min _{x} Y_{1}=(1-\beta) f^{L}(x)+\beta f^{U}(x)$

$\min _{x} Y_{2}=f^{U}(x)-f^{L}(x)$

$\mathrm{f}^{\mathrm{L}}(\mathrm{x})=\operatorname{minf}(\mathrm{x}), \mathrm{f}^{\mathrm{U}}(\mathrm{x})=\operatorname{maxf}(\mathrm{x})$

In equation (20), 6 represents the degree of preference of the decision maker for the risk of the interval gray number; $f^{L}(x)$ indicates that the uncertainty parameter in the function takes the lower limit of the gray number of the interval, and $f^{U}(x)$ represents the upper limit of the gray number of the interval in the uncertain parameter of the function. The second objective function (21) is equivalent to minimizing the variance of the uncertain objective function and reducing the range of the objective function.

\section{Uncertain constraints transformation}

Comparing the interval gray numbers with the possibility of interval order relations, many achievements have been made in the possibility study, and many possible construction methods are proposed. Nakahara et al. proposed a probability formula based on fuzzy sets. Kun du proposed a probability formula based on the transitivity of fuzzy numbers [7]. Liu S F defined the probability formula of the interval gray number according to the probability formula of interval number comparison (S Liu, Y. 2011). $\mathrm{P}(a(\otimes) \leq b(\otimes)) \geq \gamma$, $\gamma=\frac{\min \left\{l_{a}+l_{b}, \max (\bar{b}-\underline{a}, 0)\right\}}{l_{a}+l_{b}}$

And, $a(\otimes) \in[\underline{a}, \bar{a}], b(\otimes) \in[\underline{b}, \bar{b}], l_{a}=\bar{a}-\underline{a}, l_{b}=\bar{b}-\underline{b}$

$\gamma$ represents the confidence level of the uncertainty in the constraint function, and the value of $\gamma$ reflects the constraint violation risk through the variable. The smaller the value of $\gamma$, the lower the cost optimization, but the optimization satisfaction will be reduced. Conversely, the risk of constraint violation lower, the higher the satisfaction of the optimized results, and the higher the cost. These two confidence levels are directly related to the objective function, and the value will directly affect the optimization result of the total cost. Theoretically, without considering the influence of uncertainties in the constraints, the value of the uncertainty is 
unknown. When $\underline{b}=\bar{b}$ the interval gray number $\mathrm{b}(\otimes)$ is a certain number $b$, at this time, $P(a(\otimes) \leq b)=\frac{\left\{\min \left(l_{a}, \max (b-\underline{a}, 0)\right\}\right.}{l_{a}}$

The same reason, $P(a \leq b(\otimes))=\frac{\left\{\min \left(l_{\mathrm{b}}, \max (\bar{b}-a, 0)\right\}\right.}{l_{b}}$

Uncertain constraints $g_{u}$ variables contain interval gray numbers, so, $\mathrm{g}_{\mathrm{u}} \in\left[\underline{g}_{u}, \bar{g}_{u}\right]$, and $\mathrm{g}_{\mathrm{u}}(X) \leq[\underline{b}, \bar{b}]$ (eq. (18)), that is $g_{u} \leq b(\otimes)$ equivalent to $b(\otimes) \geq g_{u}$, according to the definition of the interval gray number possibility, it can be converted into $P\left(b(\otimes) \geq \mathrm{g}_{\mathrm{u}}\right)=\frac{\left\{\min \left(l_{b}+l_{g_{u}}, \max \left(\bar{b}-\underline{g}_{u}, 0\right)\right\}\right.}{l_{b}+l_{g_{u}}}$

When the uncertainty constraint is an equation, equivalent to $d(\otimes) \in[\underline{d}, \bar{d}]$ Whitening into a concrete real number, $h_{v}(X)=[\underline{d}, \bar{d}]$ (eq. (19)) can be converted into

$$
\left\{\begin{array}{l}
h_{v}(\mathrm{X}) \geq \underline{d} \\
h_{v}(\mathrm{X}) \leq \bar{d}
\end{array}\right.
$$

Using the above conversion method, the objective function and the constraint conditions of the production plan model constructed above are equivalently converted.

\section{Equivalent Transformation}

According to the decision maker's preference and the variance of the uncertain objective function uses the interval gray-order order relationship $\leq_{C R}$ to convert the original uncertainty objective function into certainty.

In the above-mentioned uncertain LPGP production planning model, the constraints eq. (8), eq. (10), eq. (11), eq. (12), eq. (13), eq. (14) and eq. (15) contain the constraints of the interval gray parameters, and these constraints and eq. (18) have the same style. Other deterministic constraints do not require conversion. Based on the introduction in the previous chapter, introduce the interval gray number probability $y$ and convert the equations (25) and (26) into deterministic forms. Objective function 1 conversion is as follows:

$$
\begin{aligned}
& \min _{x} Y_{1}=(1-\beta) f^{L}(x)+\beta f^{U}(x) \\
& \min _{x} Y_{2}=f^{U}(x)-f^{L}(x) \\
& \text { s.t. } Q_{i j}+O_{i j}+I_{i(j-1)}+D D_{i j}-I_{i j}-D D_{i j} \leq \overline{\mathrm{D}}_{i j} \\
& \text { (30) } Q_{i j}+O_{i j}+I_{i(j-1)}+D D_{i j}-I_{i j}-D D_{i j} \geq \overline{\mathrm{D}}_{i j} \\
& P_{1 j}\left(\sum_{i=1}^{N} e_{i}(\otimes) Q_{i j} \leq \lambda W_{j}\right) \geq \gamma_{1 j} \\
& \text { (32) } P_{2 j}\left(\sum_{i=1}^{N} e_{i}(\otimes) O_{i j} \leq \eta_{j} \lambda W_{j}\right) \geq \gamma_{2 j} \\
& P_{3 j}\left(\sum_{i=1}^{N} \alpha_{i}(\otimes)\left(Q_{i j}+O_{i j}\right) \leq T M_{\text {max }}\right) \geq \gamma_{3 j} \\
& \text { (34) } P_{4 j}\left(\sum_{i \in W} I W_{i j} v_{i}(\otimes) \leq I W_{j} U_{\text {max }} \quad\right) \geq \gamma_{4 j} \\
& P_{5 j}\left(\sum_{i \in P} I P_{i j} v_{i} U_{\text {max }} \leq I P_{j} U_{\text {max }}\right) \geq \gamma_{5 j} \\
& \text { (8) } \\
& \text { (10) , } \mathrm{j}=1,2,3 \ldots
\end{aligned}
$$

In the above equation, constraint equation (7) equivalent conversion eq. (29) and eq. (30), and the equations (32) to (37) $\gamma_{i j}$ are confidence levels and $0 \leq \gamma_{i j} \leq 1$. Equations (28) and (29) have the same dimension and are suitable for linear weighted summation. According to the risk preference of the decision maker, the corresponding ideal points are given the values $Y_{1}^{*}$ and $Y_{2}^{*}$, and the target cost function is converted to a single objective function.

$$
\text { (38) } \min _{\mathrm{x}} \mathrm{Y}=\sqrt{\left(\mathrm{Y}_{1}-\mathrm{Y}_{1}^{*}\right)^{2}+\left(\mathrm{Y}_{2}-\mathrm{Y}_{2}^{*}\right)^{2}}
$$


The smaller the value of $Y$ will cater to the decision maker's preference.in the actual production process, not only should the cost be controlled within a certain range, but also should considered the market satisfaction. The paper uses the delayed delivery rate of each product to measure the market satisfaction. It is known from equation (5) that the lower delay delivery cost, the greater the customer satisfaction in the market.

\section{Case Study}

A. Case Description

The case was extracted from the production process of parts of an airborne equipment company. The production process combines make to order and make to stock methods to make production plans, that is produced products rely on orders. The company is looking for an effective way to optimize production planning within the limits of existing resources and capabilities. Assume that the company will complete the production task of $3(M=3)$ products consisting of $5(N=5)$ consecutive production planning stages in one quarter. Assume that the series of products of the 6SL3210-5BB17-5UVO in the initial stage of production are 23OV-A, $230 \mathrm{~V}-B$, and $230 \mathrm{~V}-C$, respectively, $I_{11}=200, I_{21}=100, I_{31}=300$, requiring 28 laborers per day, $\eta_{j}=0.25$. Final production of the final stage of products $I_{15}=200, I_{25}=100, I_{35}=$ 200. It is assumed that the inventory area occupied by each unit of product is 1 and the cost is the same, and the personnel are changed $[0,5]$ per month in each production stage. According to the market forecast demand of the products,

shows the quantity of materials or products required to process and assemble the three products in different production planning periods (production stages) from August to October of a certain financial year.

In order to facilitate the comparison of the effects of constraints on a production stage, it can be assumed data is as follow.

Table 1 each stage product demand (piece)

\begin{tabular}{lllrll}
\hline Product(i) & \multicolumn{1}{c}{ Stage(j) } & 2 & 3 & 4 & 5 \\
\cline { 2 - 6 } & \multicolumn{1}{r}{1} & {$[1100,1360]$} & {$[1160,1450]$} & {$[1300,1500]$} & {$[1100,1250]$} \\
\hline $\mathbf{D}_{\mathbf{1 j}}$ & {$[980,1220]$} & {$[600,630]$} & {$[720,770]$} & {$[680,760]$} & {$[550,620]$} \\
$\mathbf{D}_{\mathbf{2 j}}$ & {$[730,790]$} & {$[660,0)$} & \\
$\mathbf{D}_{\mathbf{3 j}}$ & {$[1860,2200]$} & {$[2020,2550]$} & {$[1560,2100]$} & {$[1750,1980]$} & {$[1680,1800]$} \\
\hline
\end{tabular}

Table 2 Product cost (yuan/piece)

\begin{tabular}{lllll}
\hline Product(i) & \multicolumn{1}{c}{$\mathbf{O P}_{\mathbf{i j}}$} & $\mathbf{H}_{\mathbf{i j}}(\otimes)$ & $\mathbf{\omega}_{\mathbf{i j}}$ & $\mathbf{p}_{\mathbf{i j}}$ \\
\hline $\mathbf{i}=\mathbf{1}$ & {$[11,15]$} & {$[17,23]$} & {$[0.36,0.41]$} & {$[0.66,0.71]$} \\
$\mathbf{i}=\mathbf{2}$ & {$[19,25]$} & {$[29,38]$} & {$[0.41,0.49]$} & {$[0.61,0.69]$} \\
$\mathbf{i}=\mathbf{3}$ & {$[7,12]$} & {$[11,18]$} & {$[0.35,0.39]$} & {$[0.55,0.59]$} \\
\hline
\end{tabular}


Table 3 Labor cost (yuan/man-day)

\begin{tabular}{cccc}
\hline $\begin{array}{c}\text { Stage(j } \\
\text { ) }\end{array}$ & Labor cost & $\begin{array}{c}\text { Layoff } \\
\text { cost }\end{array}$ & $\begin{array}{c}\text { Hire } \\
\text { cost }\end{array}$ \\
\hline 1 & 102 & 50 & 65 \\
2 & 102 & 50 & 65 \\
3 & 102 & 50 & 65 \\
4 & 102 & 50 & 65 \\
5 & 102 & 50 & 65 \\
\hline
\end{tabular}

Table 4 Production capacity constraint and coefficient of penalty

\begin{tabular}{lllll}
\hline Stage(j) & $\begin{array}{l}\text { Semi-finished } \\
\text { inventory(piece) }\end{array}$ & $\begin{array}{l}\text { Product } \\
\text { inventory(piece) }\end{array}$ & $\begin{array}{l}\text { Machine running } \\
\text { time(hour) }\end{array}$ & $\begin{array}{l}\text { Delay } \\
\text { penalty }\end{array}$ \\
\hline$j=1$ & 3000 & 5000 & {$[1020,1580]$} & 5000 \\
$j=2$ & 3000 & 5000 & {$[1500,1780]$} & 5000 \\
$j=3$ & 3000 & 5000 & {$[1500,1780]$} & 5000 \\
$j=4$ & 3000 & 5000 & {$[1500,1780]$} & 5000 \\
$j=5$ & 3000 & 5000 & {$[1200,1600]$} & 5000 \\
\hline
\end{tabular}

Table 5 per unit of product parameter

\begin{tabular}{ccc}
\hline Product(i) & $\begin{array}{c}\text { Labor time } \\
\text { (hour/piece) }\end{array}$ & $\begin{array}{c}\text { Machine } \\
\text { (hour/piece) }\end{array}$ \\
\hline 1 & 1.0 & {$[0.9,1.1]$} \\
2 & 1.3 & {$[1.2,1.5]$} \\
3 & 1.1 & {$[0.7,0.9]$} \\
\hline
\end{tabular}

\section{B. Result analysis}

The interval planning method is used to transform the multi-objective grey parameter production model into a deterministic single-objective linear programming model and Use the LINGO11.0 software to solve. The optimization cost results when the interval gray number probability $y$ and the decision maker preference coefficient $B$ take different values are shown in Table 7. Table 8 shows the optimization results at different constraint levels, and Table 9shows the multiple stages of different possibilities $B=0.5$. 
Table 6 Optimization results with different values coefficient

\begin{tabular}{|c|c|c|c|c|c|c|}
\hline & \multicolumn{2}{|c|}{$\gamma=0.0$} & \multicolumn{2}{|c|}{$\gamma=0.5$} & \multicolumn{2}{|c|}{$\gamma=1.0$} \\
\hline & $\min Y_{1}$ & $\min Y_{2}$ & $\min Y_{1}$ & $\min Y_{2}$ & $\min _{1}$ & $\min _{2}$ \\
\hline $\begin{array}{l}\boldsymbol{\beta} \\
=0.0\end{array}$ & 264842 & 80240 & 272619 & 80774 & 270997 & 81322 \\
\hline $\begin{array}{l}\boldsymbol{\beta} \\
=0.3\end{array}$ & 281142 & 80246 & 287283 & 80780 & 294730 & 81326 \\
\hline $\begin{array}{l}\beta \\
=0.5 \\
\beta\end{array}$ & 297661 & 80242 & 300810 & 80776 & 323153 & 81324 \\
\hline $\begin{array}{l}\beta \\
=1.0\end{array}$ & 323811 & 80244 & 325194 & 80778 & 337129 & 81326 \\
\hline
\end{tabular}

Table 7 when $6=0.5$ different possible optimization results

\begin{tabular}{lcccccc}
\hline $\begin{array}{l}\text { Confidence } \\
\text { Level }\end{array}$ & \multicolumn{2}{c}{$\begin{array}{c}\text { 3products with 5stages } \\
\text { regular } \\
\text { time }\end{array}$} & overtime & Labor & MinY1 & MinY2 \\
& \multicolumn{2}{c}{} & & & & \\
\hline $\boldsymbol{\gamma}=\mathbf{0 . 0}$ & 19321 & 412 & 198 & 297661 & 80242 \\
$\boldsymbol{\gamma}=\mathbf{0 . 5}$ & 18005 & 456 & 195 & 300810 & 80776 \\
$\boldsymbol{\gamma}=\mathbf{1 . 0}$ & 17927 & 851 & 201 & 323153 & 81324 \\
\hline
\end{tabular}

As see from the results, the smaller the values of $\gamma$ and 6 , the lower the total cost. As $\gamma$ increases from 0 to 1 , the sum of the objective functions $Y_{1}$ and $Y_{2}$ becomes larger, but the sum of the production of normal production and overtime production is decreasing, because the larger $y$ makes the constraint more strict, resulting in production costs. Increase and decline in production capacity. As the $v$ decreases, the machine's normal production capacity constraints become weaker per day, and the products that are regular produced can meet the demand of the market, and the overtime output will decrease. When $\gamma=1.0$, it means that the market demand cannot be met. Due to the limitation of the total operation time of the machine every day, the enterprise needs to consider outsourcing or purchasing new equipment at this time and cannot work overtime.

$\beta$ indicates the degree of preference of the decision maker for risk. It can be seen from the optimization results that the possibility of constraints has a great influence on the optimization results. Optimistic decision makers always choose the smaller $b$ and the smaller constraint probability $\gamma$, so as to maximize the operational capability of the production equipment. However, there is also the risk that the target will fluctuate too much, because too small a constraint may mean that the constraint is invalid. Conservative decision makers will choose a larger $b$ and possible degree of constraint, maximizing the ability of the equipment to meet orders and safety stock requirements. In the actual production process, $\gamma=1.0$ cannot be obtained, because the operation equipment is close to the overload operation for a long time, which is very likely to cause equipment failure and affect the regular production of the enterprise. The running time of the equipment is too short to maximize the effectiveness of the machine. Therefore, actual production and decision makers are required to find a range of equipment running time

Table 8 shows that the decision makers are neutral at $B=0.5$, and the parameters of each production stage change with the constraint level. The results show that the smaller the 
constraint level, the easier it is to obtain a better optimization goal, but the small constraint may make the constraint become an invalid constraint. Therefore, for the specific objectives of the enterprise, the decision maker can judge the value of the constraint condition of the enterprise based on the research result.

\section{Conclusions}

In this paper, the interval gray number in grey system theory is used to characterize multiple uncertain parameters in traditional production planning activities, and the influence and correspond of multiple uncertain parameters in the production planning process of small batch multi-production stage products are studied. And giving the general solution to such problems, which provides a reference idea and method for decision makers to formulate reasonable production plans in an uncertain environment. The gray parameter linear programming model is used to deal with the uncertainty production planning problem, and the method of dealing with the uncertainty problem based on the probability distribution or membership function is extended.

Further research as the following. (1) Starting from the optimization algorithm of grey parameter production planning model, study the nonlinear production planning model of objective function and constraint interval programming, and use the mixed penalty function method or feasible direction method to solve the problem. (2) When a parameter is subject to a certain probability distribution feature, it is considered to combine the gray number of the interval and the random plan to characterize the

parameters, and further explore the hybrid production planning model to obtain More useful value.

\section{References}

Song, L., \& Hu, Z. (2015). Dynamic flexible job shop scheduling research based on rolling time domain optimization strategy. Modern Manufacturing Engineering.

Birge, J. R., \& Louveaux, F. (2011). Introduction to stochastic programming. Springer, 49(8), 897-898.

Sun, G., Yuan, Z., Geng, T., Wang, Y., Wei, Z., \& Zang, H. (2017). Robust stochastic optimal dispatching of virtual power plant containing plug-in electric vehicles. Automation of Electric Power Systems, 41(6), 44-50 and 79.

Afzali, A., Rafsanjani, M. K., \& Saeid, A. B. (2016). A fuzzy multi-objective linear programming model based on interval-valued intuitionistic fuzzy sets for supplier selection. International Journal of Fuzzy Systems, 18(5), 864-874.

Khalilidamghani, K., Abtahi, A. R., \& Ghasemi, A. (2015). A new bi-objective location-routing problem for distribution of perishable products: evolutionary computation approach. Journal of Mathematical Modelling \& Algorithms in Operations Research, 14(3), 287-312.

Qiang, F., \& Zhao, K. (2016). The robust optimization method of aircraft fleet scheduling under uncertain operational support time. First International Conference on Reliability Systems Engineering.

Nakahara, Y., Sasaki, M., \& Gen, M. (1992). On the linear programming problems with interval coefficients. International J of Computers \& Industrial Engineering, 23(1-4), 301-304. 
INTERNATIONAL JOURNAL OF ACADEMIC RESEARCH IN BUSINESS AND SOCIAL SCIENCES Vol. 9, No. 5, May, 2019, E-ISSN: 2222-6990 @ 2019 HRMARS

The Corresponding Author

Yanfeng $\mathrm{CHU}$

Email: yanfengc@nuaa.edu.cn 